\title{
O Acordo sobre os Direitos da Propriedade Intelectual relacionados ao Comércio (Trips) e seus efeitos no Ordenamento Jurídico Brasileiro
}

\section{Resumo}

A legislação que protege a propriedade intelectual no Brasil foi diretamente afetada por normas oriundas de um acordo internacional que estabeleceu orientação que se caracterizou principalmente por vincular a criação intelectual a questões prioritariamente econômicas.

\section{Abstract}

The legislation concerned with the intellectual property in Brazil has been directly affected by rules originated from an international accord that has established orientation which is mainly characterized by linking intellectual creation to questions the economics.

\section{1 - Introdução}

Em nosso trabalho, buscamos abordar os pontos mais relevantes no que diz respeito à incidência do Trips, acordo cuja sigla em inglês significa Trade Related Aspects of Intellectual Property Rights (ou Acordo sobre os aspectos dos Direitos da Propriedade Intelectual relacionados com o Comércio).

Esclarece Maristela Basso que tal acordo faz parte do Acordo Constitutivo da Organização Mundial dó Comércio (OMC) em seu anexo 1C. Tal acordo é "também conhecido como "ata final da rodada do Uruguai' e entrou em vigor em $1^{\circ}$ de janeiro de 1995. Foi assinado pelo Brasil em
Marraqueche, em 15 de abril de 1994 (Diário Oficial da União de 19.12.1994) e promulgado pelo Decreto Presidencial no 1355, de 30 de dezembro de 1994 (publicado no Diário Oficial da União de 31 de dezembro de 1994)", sendo que "o ato de ratificação foi depositado em Genebra, junto ao diretor geral do GATT, em 24.12.1994"'.

Freqüentemente, encontramos críticas à Organização Mundial do Comércio, principalmente no que tange aos interesses dos países desenvolvidos, quase sempre contrapostos aos dos países em vias de desenvolvimento (eufemismo constantemente utilizado por parte do pensamento acadêmico e pela maioria da imprensa para designar os países subdesenvolvidos).

É fato que os países subdesenvolvidos não possuem nem a organização, nem o poder econômico e tampouco o poderio militar, para fazer valer seus interesses na arena internacional.

Como demonstra Celso Lafer, "os interesses dos países subdesenvolvidos, regra geral, não têm organização suficientemente capaz de conferir-lhes força política para poder alterar pautas de conduta vigentes e, conseqüentemente, reformular as características atuais do Direito Internacional Econômico que chancela a presente distribuição internacional de recursos, responsável pela bissegmentação do sistema internacional".

$\mathrm{Na}$ verdade, pondera o autor, a solução mais adequada seria o recurso às alternativas institucionais ou ainda a busca "de novos meios de fortalecer instituições existentes, de tal forma que estas

\footnotetext{
* Doutor e Mestre em Direito Civil pela Faculdade de Direito da Universidade de São Paulo.

${ }^{\prime}$ Cf. BASSO, Maristela. Direito Internacional da Propriedade Intelectual. Porto Alegre: Livraria do Advogado, 2000. p. 19, em nota de rodapé $n^{0} 1$.
} 
passem a assegurar mais efetividade aos interesses dos países subdesenvolvidos"2.

Nessa linha de raciocínio, parece mais razoável alterar a política de crítica sistemática à Organização Mundial do Comércio e substituí-la por uma visão mais pragmática das questões que venham a violar os interesses nacionais.

Parece inevitável concluir que, no contexto atual, não há como combater qualquer abuso dos países desenvolvidos de forma isolada e, mesmo a união regional (extremamente heterogênea, como demonstra a polêmica Mercosul x Alca), não deve produzir qualquer efeito a curto ou a médio prazo.

Portanto, resta ao ordenamento jurídico interno, no qual cada vez mais o conceito de soberania encontra-se relativizado, render-se às diversas pressões existentes no âmbito internacional.

Contudo, não pretendemos aqui adotar o discurso terceiro-mundista dos anos setentas, em que os países não alinhados (entre os quais a Índia seria um exemplo marcante) contavam com a vantagem de não existir a hegemonia de nenhuma superpotência.

Nos anos noventas, as decisões políticas estavam cada vez mais atreladas ao modelo econômico adotado, e o ordenamento jurídico seguia a mesma tendência.

Portanto, não podemos analisar as mudanças ocorridas nesse período sem que sejam destacados os fatores econômicos que condicionam a elaboração das normas jurídicas.

Não que a influência econômica sobre as normas seja um fenômeno recente, vez que Fábio Nusdeo sustenta, com razão, que "a pressão dos fatos econômicos e dos interesses a eles ligados tenderá a moldar a legislação ou a forma da sua aplicação a fim de torná-la conveniente a tais interesses, o que não implica, necessariamente, a ilegitimidade dos mesmos".
Ainda no que tange à sua aplicação, o Direito e a Economia devem ser analisados "não tanto como duas disciplinas apenas relacionadas, mas como um todo indiviso, uma espécie de verso e reverso da mesma moeda, sendo difícil dizer-se até que ponto o Direito determina a Economia, ou, pelo contrário, esta influi sobre aquele".

E conclui o Professor Titular de Direito Econômico da Faculdade de Direito da Universidade de São Paulo que "existe, isto sim, uma intrincada dinâmica de interação recíproca entre ambos, donde torna-se indispensável para o jurista o conhecimento, pelo menos, de noções básicas de Economia e vice-versa para os economistas"

Nesse contexto, pretendemos destacar, ao menos inicialmente, a relevância desses fatores na elaboração da norma; sem esquecer, contudo, a importância da salvaguarda dos direitos resultantes da criação intelectual.

Os direitos da propriedade intelectual são, freqüentemente, apontados dicotomicamente no plano interno: a propriedade industrial é estudada pelo Direito Comercial, dado seu caráter essencialmente utilitário, enquanto o Direito de Autor é estudado pelo Direito Civil, sendo ressaltadas naquele Direito as características de fruição estética e de elevação do espírito ${ }^{4}$.

Em sentido diverso, Maristela Basso sustenta que parece um tanto ultrapassada e artificial a divisão estanque desses direitos, pregando a superação do modelo dicotômico, já que a Organização Mundial da Propriedade Intelectual (OMPI) é una e que a posição tradicional seria como sustentar que "o oceano pudesse ser dividido, ter seu curso limitado, ou sua importância ignorada ou escalonada".

Tal posição revela a importância da renovação do debate nessa questão, embora pessoalmente nos posicionemos favoravelmente, talvez por nossa

${ }^{2}$ Cf. LAFER, Celso. Comércio e Relações Internacionais. São Paulo: Perspectiva, 1977. p. 33.

${ }^{3}$ Cf. NUSDEO, Fábio. Curso de Economia: introdução do Direito Econômico. 2. ed. São Paulo: Revista dos Tribunais, p. 30.

${ }^{4}$ Com exceção da obra arquitetônica, que possui em certa medida um caráter utilitário, normalmente o Direito Autoral sustenta que existiria um caráter de mero deleite nessas obras. Em nosso país, majoritariamente, os civilistas e os comercialistas sustentam a dicotomia da propriedade intelectual, citando como exemplos dessa linha doutrinária Antonio Chaves, Fábio De Mattia, Carlos Alberto Bittar, Rubens Limongi França e Newton Silveira.

${ }^{5}$ Cf. BASSO, Maristela. op. cit. p. 47. 
própria formação civilista, à tradicional visão dicotômica.

\section{2 - Aplicação do Trips no Direito Interno}

Relata Jacques Labrunie que, atualmente, o Trips integra o ordenamento jurídico brasileiro, pois, "pelo sistema constitucional brasileiro, uma norma de Direito Internacional, tratado ou convenção, para ser aplicável no país, necessita seguir o seguinte trâmite: ser assinado pelos representantes do Brasil; ratificado pelo Congresso Nacional; e promulgado pelo Presidente da República".

Assim, "pelo sistema pátrio, não é necessária a edição de norma interna, adaptando-se ao tratado ou convenção. Passadas as três etapas mencionadas, o tratado ou convenção passa a ser aplicável pelas autoridades e tribunais brasileiros (nr 1 "O Tratado é obrigatório em virtude da ratificação, executório em virtude da promulgação, aplicável em virtude da publicação". Hildebrando Accioly, RF 126/30).

Para tanto, basta lembrar que o STF "já fixou orientação no sentido de que, seguindo a teoria monista do Direito Internacional, o tratado ou convenção internacional integra o Direito interno brasileiro, uma vez ratificado pelo Congresso Nacional e promulgado pelo Presidente da República" e, "de tal forma, o tratado ou convenção passa a valer com a mesma hierarquia das leis ordinárias (nr 2 - "uma vez incluído o tratado ou a convenção no Direito interno brasileiro, compete aos tribunais - como bem acentuou Ruy Barbosa - dar-lhes aplicação, como às demais leis)" Rubens Requião - RDM 01/246.

Nossa Constituição Federal prevê no artigo 5º,
XXVII que "aos autores pertence o direito exclusivo de utilização, publicação ou reprodução de suas obras, transmissivel aos herdeiros pelo tempo que a lei fixar", estabelecendo ainda no inciso seguinte, na alínea $a$ que existirá "a proteção às participações individuais em obras coletivas e à reprodução da imagem e voz humanas, inclusive nas atividades desportivas".

A alínea $b$ do mesmo inciso prevê também a proteção dos direitos conexos, vez que será respeitado "o direito de fiscalização do aproveitamento econômico das obras que criarem ou de que participarem aos criadores, aos intérpretes e às respectivas representações sindicais e associações".

A propriedade industrial está protegida no art. 5ำ, XXIX da Constituição Federal e todos os dispositivos aqui mencionados, enquanto direitos e garantias fundamentais são considerados como cláusulas pétreas da Constituição Federal, por força do art. $60, \S 4^{\circ}$, IV da CF.

Oartigo 65 do Trips prevê, no item 1, que "nenhum membro estará obrigado a aplicar as disposições do presente acordo antes de transcorrido um prazo geral de um ano após a data de entrada em vigor do acordo constitutivo da OMC" e, em prazo de interesse para o nosso país, possibilitou, no item 2, que "um país em desenvolvimento membro tem direito a postergar a data de aplicação das disposições do presente Acordo, estabelecida no parágrafo 1, por um prazo de quatro anos", com as exceções previstas no Trips.

Questão importante a ser levantada é sobre as datas de vigência e aplicação de Trips. Ninguém discute que o Trips é vigente no Brasil desde 1/1/95; controvérsia existe sobre a data de aplicação do Acordo.

\footnotetext{
${ }^{6}$ Cf. LABRUNIE, Jacques. Acordo de Trips e as questões controvertidas na área de patentes. In: SEMINÁRIO NACIONAL DE PROPRIEDADE INTELECTUAL, XIX, 1999. Anais. 1999. p. 84-89. Completa o mesmo autor seu pensamento afirmando que "A questão, porém, não é tão simples, sobretudo porque, caso a lei interna do país membro da OMC esteja em desacordo com o Trips, o referido membro está sujeito a sanções por parte da OMC - o que não interessa ao Brasil, de forma alguma". Entendemos que, na maioria dos casos, quando há divergência entre a LPI e Trips, há apenas um conflito aparente de normas, e não um conflito de fato. Na realidade, o Trips, em diversos aspectos, complementa a LPI. Aliás, não é a primeira vez que convivem, lado a lado, regras diferentes, porém, não conflitantes, de tratado internacional (vigente no país) e de lei ordinária. A Convenção de Paris (Decreto n⿳⺈ 635/92) e a Lei 5.772/71 (antigo Código da Propriedade Industrial) conviveram pacificamente, como normas complementares, entre 24/08/92 e a vigência da nova lei (14/05/97), havendo, inclusive, nesse sentido, o Parecer INPI/PROC/DICONS/nº PI 86/92. (p. 85).
} 
Uma corrente, encabeçada pela ABPI e por doutrinadores de monta (nr 5 - entendem que o Trips é de aplicação imediata, entre outros, Célio Borja, Jacob Dollinger, Luiz Olavo Baptista, José Roberto de Affonseca Gusmão, Luiz Leonardos, Gustavo Leonardos, Jacques Labrunie (vide RABPI no 36, p. 31, "Ainda os prazos de vigência das patentes- Trips e a nova Lei de Propriedade Industrial"), entende que o acordo de Trips é vigente e aplicável, no Brasil, desde $1 / 1 / 95$.

O INPI, através do Parecer DIRPA nº 01/07, externou o entendimento no sentido de que o Trips só seria aplicável a partir de 1/1/2000, em vista do disposto no artigo 65 do próprio Trips, que autoriza os países em desenvolvimento a postergarem a aplicação do Acordo por cinco anos.

A posição da ABPI, à qual nos filiamos, é no sentido de que o artigo 65 de Trips contemplava uma mera faculdade, disponível aos países em desenvolvimento, da qual o Brasil abriu mão, ao não exercê-la, sendo que o autor ressalvava que "de qualquer forma, a questão se o Trips é aplicável desde 1/1/95 ou 1/1/2000 perde um pouco de relevância, uma vez que estamos às vésperas de janeiro de 2000, quando ninguém mais discute se o acordo é vigente e aplicável"7.

\section{3 - O Acordo Trips e a Lei de Cultivares (Lei 9.456/97)}

A aprovação da Lei de Cultivares, para Edson Souza, provocou "expectativas de que a Lei de Proteção de Cultivares provocasse um incremento nos níveis de investimentos, principalmente do setor privado", evitando a pirataria e possibilitando ao país a inserção internacional necessária.

Contudo, apesàr da adesão à Convenção da UPOV ser apontada pelo mesmo autor como essencial, pois o país teria "de firmar diversos acordos bilaterais para o reconhecimento da proteção das cultivares brasileiras em outros países" "é na própria Lei de Cultivares, em seu artigo 11, que encontramos um grave problema ao prever que " a proteção da cultivar vigorará, a partir da data da concessão do certificado Provisório de Proteção, pelo prazo de 15 (quinze) anos, excetuadas as videiras, as árvores frutíferas, as árvores florestais e as árvores ornamentais, inclusive, em cada caso, o seu porta-enxerto, para as quais a duração será de 18 (dezoito) anos".

Sustentamos que tal previsão está em desacordo com o Trips que prevê que "a vigência de patente não será inferior a um prazo de 20 anos, contados da data do depósito".

É mais do que razoável prever que a não-observância da regra do Trips pode causar problemas extremamente significativos para o nosso país no que tange aos cultivares.

\section{4- O Acordo Trips e a Lei de Software (Lei 9.609/98)}

A Lei do Software (Lei 9.609/98) estabeleceu, em seu artigo $2^{\circ}$, que "o regime de proteção à propriedade intelectual de programa de computador é o conferido às obras literárias pela legislação de direitos autorais e conexos".

Newton Silveira ressaltou que "mantém esta lei o mesmo sistema da lei anterior (universalmente adotado, até agora) de assemelhar o direito sobre tratamento da informação ao direito de autor sobre forma de expressão, submetendo o direito do criador de software às normas gerais da lei autoral (n. 9.610, de 19-2-1998)", com a ressalva de que "o artigo $2^{\circ}$ remete a tutela da propriedade intelectual de programa de computador à lei autoral, com uma novidade: equipara-o às obras literárias".

Conclui o professor de Direito Comercial da Faculdade de Direito da Universidade de São Paulo, enfatizando que "não justifica essa tardia equiparação senão a Constituição norte-americana, que determina que o Congresso deve promover a pro-

${ }^{7}$ Cf. LABRUNIE, Jacques. op. cit. p. 85.

${ }^{8}$ Cf. SOUZA, Edson. A proteção de variedades vegetais e os direitos de propriedade intelectual. In: Revista da ABPI. São Paulo, n. 40, p. 40-48, maio/jun., 1999. 
teção aos escritos dos autores e às descobertas dos inventores", posto que "equiparar um tipo de criação a outro nunca deu certo em matéria autoral".

Inegavelmente, as críticas do autor, bastante contundentes, parecem ter procedência e justificam-se principalmente pelo fato de tal equiparação também estar prevista no Trips.

Para tanto, ressaltamos que o artigo 10 do Trips prevê que "os programas de computador, em código fonte ou objeto, serão protegidos como obras literárias pela Convenção de Berna (1971)”.

A Lei 9.610/98 elenca como obras intelectuais protegidas, no artigo $7^{\circ}$, XII os programas de computador.

São previstos como direitos morais de autor, pelo artigo 24 da Lei 9.610/98, os direitos de reivindicar a autoria da obra; de ter seu nome ligado à obra (paternidade); o de conservar a obra inédita; o de assegurar a integridade da obra; o de modificar a obra, o de retirá-la de circulação (arrependimento) e o de ter acesso a exemplar único e raro da obra para preservá-la.

A Lei 9.609/98 determina, no $\S 1$ o do artigo $2^{\circ}$ que "não se aplicam ao programa de computador as disposições relativas aos direitos morais, ressalvado, a qualquer tempo, o direito do autor de reivindicar a paternidade do programa de computador e o direito do autor de opor-se a alterações não-autorizadas, quando estas impliquem deformação, mutilação ou outra modificação do programa de computador, que prejudiquem sua honra ou reputação".

Assegura-se, por força do disposto no artigo 2 , $\S$ 2ㅇ da Lei 9.610/98, ao autor de programa de computador, a proteção pelo prazo de 50 anos que serão contados "a partir de $1^{o}$ de janeiro do ano subseqüente ao da sua publicação ou, na ausência desta, da sua criação".

Na verdade, no mundo contemporâneo, a proteção ao direito do autor vai muito além da discussão acerca da proteção do software, gerando efeitos principalmente na transmissão realizada na World Wide Web, na qual tais violações podem adquirir uma dimensão incalculavelmente maior.

José de Oliveira Ascensão, ao mesmo tempo que constata que o terceiro que coloca a obra em rede sem autorização do autor comete uma infração, indaga "qual é concretamente a faculdade, compreendida no direito de autor, que não é respeitada ao fazer-se semelhante utilização?", ressaltando a importância da questão tanto no âmbito interno como no internacional.

Isso porque, segundo o autor, no plano interno, "embora se atribua ao autor a generalidade das faculdades de utilização pública da obra, a determinação da faculdade concretamente em causa não é irrelevante porque varia o regime jurídico a que cada faculdade está submetida", enquanto "no plano internacional a dificuldade é maior, as faculdades que são internacionalmente asseguradas são típicas: são apenas aquelas que estejam especificadas em convenção internacional. Era pois necessário saber se a utilização das obras em rede atingia alguma das faculdades previstas; e, no caso negativo, disciplinar a nova faculdade que deveria ser atribuída".

Relata o conhecido jurista português que " $a$ generalidade das opiniões expendidas a este propósito propendeu no sentido de considerar que a utilização informática das obras era já vedada pelas convenções vigentes, pois correspondereria a alguma das faculdades típicas já internacionalmente previstas", concluindo, porém, que "esta forma de utilização não estava até então internacionalmente prevista", tratando-se da criação de uma faculdade nova, não se enquadrando nem como direito de reprodução, nem de distribuição e nem de comunicação ao público, tradicionalmente apontados como direitos patrimoniais do autor ${ }^{10}$.

Concluindo, acreditamos que o tema enseja e ainda ensejará diversas discussões, pois, tanto na Internet como no software estamos ainda atraves-

\footnotetext{
${ }^{9}$ Cf. SILVEIRA Newton. A Propriedade intelectual e as novas leis autorais: propriedade industrial, direito de autor, software e cultivares. 2.ed. São Paulo: Saraiva, 1998. p. 75-76.

${ }^{10}$ Cf. ASCENSÃO, José de Oliveira. O Direito de Autor no Ciberespaço. Revista da Emerj, Rio de Janeiro, v. 2, n. 7, p. 21-43, 1998.
} 
sando uma fase de transição, em que novos direitos nem sempre podem ser enquadrados nos modelos elaborados anteriormente.

\section{5 - O Acordo Trips e a Lei de Direitos Autorais (Lei 9.610/98)}

A Lei de Direitos Autorais (Lei 9.610/98) foi até além do que o Trips previa, explicitando diversos direitos e deferindo prazos bem amplos para exercê-los.

Para Newton Silveira, "com poucas exceções, mantém-se na nova lei e se acentua o espírito nitidamente empresarial da lei de direitos autorais anterior, de n. 5.988, de 1973. A nova lei é uma reescrita da lei anterior, com acréscimos, algumas correções e a supressão do intervencionismo na arrecadação de direitos autorais, finalizando com observação bastante crítica de que a Lei 9.610/98 "parece ter sido montada, como uma transparência, sobre a lei ora revogada"11.

Na obra de Carlos Alberto Bittar, atualizada por Eduardo Carlos Bianca Bittar, ressalva-se que "a vigência e a aplicação das normas subsidiárias e complementares ao texto da Lei 9.610/98, que não foram expressas ou tacitamente revogadas, sendo claro que o Código Civil continua a representar o manancial básico de referência em matéria de direitos civis, quando inexistente regra específica para a disciplina de determinada questão de cunho prático" e, "neste sentido, a nova lei de direitos autorais exerce o mesmo papel anteriormente delegado à Lei $n^{0}$ 5.988/73, o de regulamentar com caráter especial a matéria de direitos autorais e conexos" ${ }^{\prime 2}$.

A Lei 9.610 de 1996 surgiu da necessidade de rever diversos pontos da Lei 5.988/73 e, segundo José Carlos Costa Netto, foi instalada comissão para apreciar o projeto de Lei 5.430/90, com origem no Senado Federal, sendo que " $a$ Comissão, presidida pelo Deputado Roberto Brant, tendo como relator o Deputado Aloysio Nunes Ferreira, optou por oferecer - através do parecer emitido em 10/09/97 - sob o título de 'substitutivo' ao referido Projeto de Lei 5.430, de 1990, do Senado Federal e seus apensos, Projeto de Lei inteiramente calcado no formato organizativo da Lei 5.988, de 1973, e que, modificando, em trechos significativos, o conteúdo deste diploma de regência, 'altera, atualiza e consolida a legislação sobre direitos autorais e dá outras providências"”.

Tendo sido "aprovado pela Câmara Federal, o relator para o Senado Federal, Senador Romeu Tu$\mathrm{ma}$, recomendou, em atendimento à reivindicação de setores da classe artística, liderados pelo renomado ator Sérgio Mamberti, a supressão de três artigos (36, 37 e 38), que tratavam do regime jurídico da obra sob encomenda" e, "acolhida a proposta pela Comissão de Constituição e Justiça do Senado, a nova Lei de Direitos Autorais foi, afinal, votada e aprovada no início de fevereiro de 1998 pelo Senado Federal e encaminhada à sanção do Presidente da República"13.

O artigo 9ำ do Trips remete à Convenção de Berna, enquanto o artigo 12 do Trips prevê o prazo de 50 anos, quando calculado de forma diferente à da vida da pessoa física, sendo que, nessa hipótese, esses cinqüenta anos serão "contados a partir do fim do ano civil da publicação autorizada da obra ou, na ausência dessa publicação autorizada nos 50 anos subseqüentes à realização da obra, a 50 anos, contados a partir do fim do ano civil de sua realização".

No Brasil, que segue o critério, para efeitos de contagem, do fim da existência da pessoa física, o artigo 41 da Lei 9.610/98 prevê que "os direitos patrimoniais do autor perduram por 70 (setenta) anos contados de $1^{\circ}$ de janeiro do ano subseqüente ao de seu falecimento, obedecida a ordem sucessória da lei civil".

Cabe também destacar os direitos conexos ou

${ }^{11}$ Cf. SILVEIRA, Newton, op. cit. p. 61.

${ }^{12}$ Cf. BITTAR, Carlos Alberto. Direito de Autor. 3. ed. revista, ampliada e atualizada conforme a Lei 9.610, de 19 de fevereiro de 1998 por Eduardo Carlos Bianca Bittar. Rio de Janeiro: Forense Universitária, 2000. p. 16-17.

${ }^{13}$ Cf. NETTO, José Carlos Costa. Direito Autoral no Brasil. São Paulo: FTD, 1998. p. 44-45. 
direitos vizinhos (retirados do francês droits voisins), que guardam semelhanças com os direitos conferidos ao autor da obra.

Dentre os direitos conexos, temos os direitos dos artistas intérpretes ou executantes (artigos 90 a 92), os direitos dos produtores fonográficos (artigos 93 e 94) e os direitos das empresas de radiodifusão (artigo 95).

A Lei 9.610/98 estabelece ainda, no artigo 96, que, para os direitos conexos o prazo de proteção será de setenta anos "contados a partir de $1^{\circ}$ de janeiro do ano subseqüente à fixação, para os fonogramas; à transmissão, para as emissões das empresas de radiodifusão; e à execução e representação pública, para os demais casos".

O prazo de setenta anos previsto na Lei 9.610/98 também ampliou o prazo de 60 anos previsto anteriormente na Lei 5.988/73.

Em comparação com o Trips, o prazo é claramente vantajoso para todos os que detêm direitos conexos, uma vez que o artigo 14, item 5 dispõe que "a duração da proteção concedida por este acordo aos artistas-intérpretes e produtores de fonogramas se estenderá pelo menos até o final de um prazo de 50 anos, contados a partir do final do ano civil no qual a fixação tenha sido feita ou a apresentação tenha sido realizada. A duração da proteção concedida de acordo com o parágrafo 3 será de pelo menos 20 anos, contados a partir do fim do ano civil em que a transmissão tenha ocorrido".

O parágrafo 3 referido no artigo 14 diz respeito às organizações de radiodifusão, que contam com um prazo (ainda que mínimo) de vinte anos, amplamente superados pelos setenta anos concedidos pela lei brasileira.
Dessa forma, reforçamos nosso entendimento de que não há como negar que tanto o autor como os direitos conexos encontram proteção adequada, em padrões internacionais, no nosso ordenamento jurídico.

\section{6 - Conclusões}

1) $O$ acordo Trips possui aplicação no âmbito interno, não só por sua ratificação, mas também por resguardar direitos já previstos no âmbito constitucional, direitos esses considerados como fundamentais e que constam como cláusulas pétreas em nosso sistema jurídico, consoante o disposto no artigo 60, § 4을 da Constituição Federal.

2) O prazo previsto na Lei de Cultivares viola o prazo mínimo previsto pelo Trips, já que também trata de patentes.

3) Apesar de pessoalmente acreditarmos que a proteção ao software deveria ensejar a criação de um sistema híbrido, já que há tanto aplicação técnica como criação para mero deleite, prevalece a opinião de que o software deve ser protegido como direito de autor, equiparado à obra literária, posicionamento esse presente tanto no Trips como na Lei 9.609/98 (Lei do Software).

4) Enquanto o Trips repete o prazo de cinqüenta anos já previsto na Convenção de Berna e estipula que os direitos conexos terão uma proteção de vinte a cinqüenta anos, a Lei 9.610/98 garante uma proteção de setenta anos tanto para os autores como para os titulares de direitos conexos.

\section{REFERÊNCIAS BIBLIOGRÁFICAS}

ASCENSÃO, José de Oliveira Ascensão. O Direito de Autor no ciberespaço. Revista da Emerj, Rio de Janeiro, v. 2, n. 7 , p. 21-43, 1998.

BASSO, Maristela. O Direito Internacional da propriedade intelectual. Porto Alegre: Livraria do Advogado, 2000.

BITTAR, Carlos Alberto. Direito de Autor. 3. ed. revista, ampliada e atualizada conforme a Lei 9.610, de 19 de fevereiro de 1998 por Eduardo Carlos Bianca Bittar. Rio de Janeiro: Forense Universitária, 2000.

. Os direitos da personalidade. 2.ed. Rio de Janeiro: Forense Universitária, 1995.

LABRUNIE, Jacques. Acordo de Trips e as questões controvertidas na área de patentes. In: SEMINÁRIO NACIONAL DE PROPRIEDADE INTELECTUAL, XIX, 1999. Anais. 1999. p. 84-89. [s.1.] 
LAFER, Celso. Comércio e Relações Internacionais. São Paulo: Perspectiva, 1977.

NETTO, José Carlos Costa. Direito Autoral no Brasil. São Paulo: FTD, 1998.

NUSDEO, Fábio. Curso de Economia: introdução do Direito Econômico. 2. ed. São Paulo: Revista dos Tribunais, 2000.

SILVEIRA, Newton. A propriedade intelectual e as novas leis autorais: propriedade industrial, direito de autor, software e cultivares. 2.ed. São Paulo: Saraiva, 1998.

SOUZA, Édson. A proteção de variedades vegetais e os direitos de propriedade intelectual. Revista da ABPI, São Paulo, n. 40, p. 40-48, maio/jun., 1999 . 